\title{
A Study of Customer Satisfaction on After Sales Service of Two Wheelers in Kathmandu Valley
}

\author{
Sanjupa Giri ${ }^{1}$ and Kumar Thapa ${ }^{2}$
}

\begin{abstract}
The purpose of this study is to explore the relationship between various identified after-sales service attributes of Two Wheeler brands and customer satisfaction. It further intends at segregating the major after sales service as per Kano Model. This research is a quantitative research with a sample size of 280, 40 each on the basis of brands of bike and scooter. Sample is selected in a quota and convenience basis. The brands which are taken as samples includes Honda, Hero, Bajaj, Mahindra, Yamaha, Royal Enfield and others (TVS, Suzuki and VR). Kano Model analysis, frequency analysis, correlation, ANOVA test, independent sample t-test, etc. are used for data analysis. Kano model is taken as a basic model for the study.

Surprisingly, it is found that supporting after sales service has more impact on customer satisfaction than major after sales services have. Apparently, the most valued after sales service is behaviour of technicians which has the strongest and positive relation with customer satisfaction. Behaviour attributes play major role in customer satisfaction. Likewise, functional and dysfunctional questions are analyzed to carry out Kano Model Analysis. From the research, it is found that Spare part supply, Warranty, Bike wash and Service camp are the must be requirements. Likewise, Repair and Maintenance, Customer Care, Inspection and Mobile Van (office hours) are regarded as one dimensional services. And, Driving Orientation and 24 hours Mobile Van service are regarded as Attractive services. At present, $63 \%$ of customers are satisfied with the after sales service and $10 \%$ are very satisfied with the current after sales service. This study is significant to distributors of two wheelers and parent companies, as they can formulate after sales service strategies by understanding the present satisfaction level of customers and degree of each after sales service attributed to satisfy the customers.
\end{abstract}

Key words: Aftermarket, Customer Satisfaction, Kano Model, Descriptive and Inferential Analysis

I Ms. Giri is working at Citizens Bank International limited as a management trainee in Corporate Credit Business Unit.

2 Mr. Thapa is a Principal of John Dewey School, Kathmandu

Corresponding email: meetsanzupa@hotmail.com 


\section{Introduction}

Customer Satisfaction is a measure of how products and services provided by a company meet or surpass customer expectation. Nowadays, mere products cannot satisfy customers' expectation; customers demand instant after sales service as well. Customer satisfaction largely depends on how customers are treated before, during and after the sales is made, along with product or service utility.

According to Philip Kotler, after sales service is a service provided by the company to a customer after the sale. After-sales services, a high-margin business, account for a large chunk of corporate profits. According to a 1999 AMR Research report, businesses earn $45 \%$ of gross profits from the aftermarket, although it accounts for only $24 \%$ of revenues. The cost of attracting a new customer is estimated to be five times the cost of keeping a current customer happy and hence, businesses are conducting customers' satisfaction survey to understand needs and wants of the customer.

According to Automotive news (May 5, 2014), General Motors is planning to shorten its customer satisfaction survey via online ratings and reviews which will gather faster and effective feedback. Similarly, as per the J.D. Power Asia Pacific 2014 India Customer Service Index (CSI) (Based on 1000-point scale), the top three companies which top the list on customer satisfaction are Maruti Suzuki 890, Honda Cars India - 863 and Hyundai India - 863.

Nepal, being an importer of Two Wheelers, changing features to customize and satisfy the needs of the customer is not an option. In this competitive market, one of the strategies to satisfy the customer and probably make them loyal is by delivering effective after sales services. Though Two Wheeler brands (Honda, Hero, Bajaj, Mahindra, Royal Enfield, Yamaha, Suzuki, TVS etc) have managed to provide after sales services from their various service centres, they are still unaware about how many of their customers are satisfied and which after sale service has the capacity to satisfy customers. Hence, this research answers the questions like: In what ways are the after sale services being offered? Are the customers' satisfied from the after sales service? Which after sales service is highly valued by the customer? Hence the major objectives of the research is to examine the relationship between identified after sale services and customer satisfaction in the two wheeler industry and to segregate the major identified after sales service as per Kano Model.

A clear analysis of aftermarket of two wheelers, identification of true position in terms of after sales service, knowledge of attractive, performance and threshold attributes of after sales services, assessment of needs of the customers, etc. will be 
the benefits for national distributors from this study. Likewise, Parent companies will have a clear picture of condition of after sales service and customer satisfaction level in Kathmandu Valley which will be helpful in making future after sales servicedecisions.

Most of the past studies focus more on product attributes rather than after sales service attributes in their research and examine a single brand, while this study examines the pure aftermarket service attributes of two wheeler industry and its relationship with customer satisfaction, and it also analyses the after sales condition of the industry as a whole. Moreover, it includes the behaviour aspect of the service as well which most of the past studies lack.

\section{The Literature Review}

After sales service plays a great role in customer satisfaction. The relationship between after sales service and customer satisfaction is positive $(r=0.463, P \leq 0.001)$ and there is positive correlation between after sales service and intent to repurchase ( $\mathrm{r}=0.583, \mathrm{P} \leq 0.001$ ) (Maghsoudlou, Mehrani and Azma,2014, "The Role of AfterSales Service in Customer Satisfaction: Case Study : Samsung House Appliances). Out of 100 customers of Tata at Jharkhand, $66 \%$ were satisfied with the after salesservice provided by the showroom, $60 \%$ of the customers agreed that staffs were available in timely manner, $20 \%$ said that they had to wait longer hours to get the service, $26 \%$ agreed that the staff were friendly and cheerful in dealing with them, $44 \%$ agreed that staff greeted them and offered help as well, $40 \%$ agreed that staff were skilled and knowledgeable, $42 \%$ agreed that staff answered their problems, and $40 \%$ agreed that facilities were provided in waiting room (Mishra, 2014 "A study on relation between effective after sales service and customer overall satisfaction at TATA motor's with special reference to Ramgarhia Automobiles Ramgarh Cantt, Jharkhand"). Customer satisfaction largely depends on product features, price and aftermarket. Price, mileage, pickup and design have significant effect on customer satisfaction of Honda at Tirupati (Yuvaraju and Rao, 2014, "Customer Satisfaction towards Honda Two Wheelers: A case study in Tirupati"). Customers are satisfied with price, design, safety, mileage, interior space, status, brand name, comfort level, spares and after sale service of Tata motors passenger vehicles. Price was the most influencing and primary determinant, mileage and interior space were considered to be secondary determinants. After sale service were found to be less influencing (Dua and et.al, 2013). As per the research of Ladokun, Adeyemo, and Ogunleye (2013), Product delivery; Installation and Warranty were significantly joint predictors of customer satisfaction. Fuel Economy, Comfort, Spare parts, Price, value for money, mileage, maintenance, radius and parking have significant effect on customer satisfaction of Maruti Suzuki. Discounts, seasonal offers and delivery period were considered 
valuable by the customer (Singh and Srivatava, 2013, "Factors Affecting Customer Satisfaction: A Study on Maruti Suzuki").

People of Zonguldak rate warranties at highest (72\%) after sales service out of services like warranties, transportation, installation and free customer hotlines. Transportation comes to the second place; installation to third and free customer hotlines comes to the fourth place (Cabuk, Karayilmazlar and Turedi,2012, "A study on evaluation of after sales services in the furniture sector"). Similarly, Srinivasan and et.al (2011) made a research on "A Study on Customer Satisfaction with Reference to Product Characteristics and Services of Schwing Stetter India Private Limited" and infer that there is no relationship between quality of product and value for money. There is no relationship between performance and complaint handling. However, there is a very high degree of positive correlation between quality of product and after sales service.

There are some factors of after sales services which influence consumer buying behaviour. Economic spare parts have strong impact on consumer buying behaviour as compared to easy availability of spare parts and easy availability of mechanic (Saeed and et.al, 2013, "Impact of 'After Sales Service' on 'Consumer Buying Behavior' in Sahiwal Pakistan"). Consumer buying decision also depends on demographic factor of the customer. Sales are strongly correlated with age group and gender of the consumers whereas income level has nothing to do with purchase decision of customers (Shaikh, 2012).

Service dimensions are one of the major determinants of customer satisfaction. In telecom sector of Pakistan, service quality dimensions (like reliability, technical service, image, assurance etc) and customer satisfaction have positive correlation (Sandhu and et.al, 2013), whereas in China's Auto industry fairness, empathy, reliability and convenience have significant positive impact on satisfaction, but responsiveness has no significant positive impact on satisfaction. However, trust has a significant positive impact on commitment (Gang and Shuqin, 2012). Accepting attitude of the company, service personal attitude, increasing processing speed, after sales service like maintenance, supply of spare parts, replacement and most importantly, time to recover service etc will be helpful in after sales service recovery (Fenghua, Xiaoye and Yuqing, 2013).

SERVQUAL model is widely used in measuring service quality. Five dimensions of SERVQUAL model: Tangibles, Reliability, Responsiveness, Assurance and Empathy, are analysed in terms of Expectation and Perception and the gap range is analysed for the conclusion. In assessing the service quality of bank in Lahore, Pakistan, it was found that banking institutions are exceeding customer expectations in three dimensions i.e. "Tangibles", "Reliability" and 
"Responsiveness" and lacking in other two dimensions "Assurance" and "Empathy" (Ilyas and et.al, 2013). Whereas survey in a local bank at Chittagong showed that it does not have ability to exceed customer expectation in any of the SERVQUAL dimensions. In fact, customers are highly dissatisfied in terms of Responsiveness (Tazreen, 2012). Product quality and social responsibility are major variables affecting customer satisfaction and customer satisfaction increases with better service delivery (Hussain, Batti and Jilani, 2011) "An empirical analysis of after sales service and customer satisfaction"). Service delivery is prime determinant of customer satisfaction. 50\% vehicles were delayed due to overload of service centre which causes customer dissatisfaction and that problem can be solved by installing automated machines for washing and cleaning of vehicles and working shift can also be managed Katarne and Sharma (2010).

Along with SERVQUAL model, Kano Model is also used in measuring customer satisfaction. In this regard, Mustofa and Abebe (2012), made a study on "Effect of after sale services on customer satisfaction and loyalty in Automotive Industry of Ethiopia" where two brands MOENCO and Holland Car are taken for the study. It is found that for Holland car PLC after sale service customers, maintenance, spare part supply and inspection are one dimensional requirement, while online (telephone) service, car washing and documentation services are indifferent requirements. In addition, warranty is must be requirement. Moreover training (driving orientation) is reverse requirement for Holland Car PLC customers. For MOENCO, car washing is attractive requirement, while maintenance service, spare part supply service and inspection services are one-dimensional requirements. In addition, online (telephone) service, and documentation services are indifferent requirements. Moreover training (driving orientation) is reverse requirement for MOENCO after sale service customers. They also found out that after sale service components like car washing service, telephone service, maintenance service, spare part supply service and warranty service are found significantly related to overall satisfaction level of after sale service of customers and they have no equal contribution to overall satisfaction levels. However, they found that driving orientation and documentation services are not significantly related to overall satisfaction of customers. By using Kano's model of customer satisfaction to explore customers' stated needs and unstated desires and resolve them into different categories can be used as a basis for product development, especially for quality function deployment Matzler and Hinterhuber (1998). The must-be, satisfier, and delight categorization system developed by Kano is a popular means of better understanding the key differences between customer satisfaction and customer delight. Must be requirement consists of the basic criteria of goods or services that result in extreme customer dissatisfaction if not fulfilled. A consumer's degree of satisfaction among satisfiers is related to the level of 
fulfilment- higher the level of fulfilment, greater the level of customer satisfaction. Attractive requirement basically deals with customer delight if met but there will be no feeling of dissatisfaction if not met. Berman (2005).

Research has found that customer satisfaction leads to loyalty. Satisfaction on technical-functional (safety, vehicle's manoeuvrability and vehicle comfort quality) of the automobile is the core factor to determine the loyalty. The satisfaction with the global cost of the vehicle (associated with price, fuel costs, repair costs and replacement part costs) and with the dealer after sales service (reception, delivery and vehicle service realized) falls under second place (Lucero, Legorreta and Cervantes, 2007). Hallowell (1996) made a study on "The relationships of customer satisfaction, customer loyalty, and profitability: an empirical study" and concluded that customer loyalty in terms of customer retention, relationship tenure, accounts cross sell and service cross sell is related with overall satisfaction and satisfaction with respect to service index and price index.

From the literature review, it was found that most of the past studies have focused their research more on product attributes (price, design, features etc) rather than after sales attributes. Likewise, most of the past studies have not considered the contribution of human factor i.e. behavior aspect in customer satisfaction. Moreover, most of the past studies have a limited sample size of 100 and their studies are confined with only brands like Hero or Maruti which only reflect the scenario of a company but not the condition of the industry as a whole.

However, this research focuses on core after sales service attributes and human aspect of service of two wheeler industry. Moreover, this study includes sample of almost every brand of the two wheeler industry present in Kathmandu Valley making sample size 280. Hence, this research provides a better insight in all the shortcoming of the past studies and fulfills the research gap.

\section{The Methodology}

The research is segregated into two parts: (1). Kano Model analysis (2) Analysis of the customer satisfaction in terms of major and supporting after sales services.With reference to study made by Matzler and Hinterhuber (1998), Sauerwein and et.al (1996), and Mustofa and Abebe (2012), we come up with the following ideas about Kano Model.

\section{1 The Basic Model}

Kano Model (1984) which was developed by Noriaki Kano and his colleagues to categorize the attributes of a product or a service; based on how well they are able to satisfy customers' needs, is used to categories the major after sales service on the basis of Threshold Attribute, Performance Attribute and Excitement Attribute. 
Kano model states that the relationship between the performance of a product attribute and satisfaction/ dissatisfaction level is not necessary linear. Some attributes can be asymmetrically related with satisfaction/ dissatisfaction levels. According to principle, product attributes are classified into one of the five categories.

- Attractive: Those qualities that the customer is not expecting, but receives as a bonus.

- One-dimensional: The better the companies are meeting these needs, the happier the customers are

- Must be: The essential character of the product or service which must be present at any cost, else the customer will go somewhere else.

- Indifferent: These attributes refers to aspects that are neither good nor bad, and they do not result in either customer satisfaction or customer dissatisfaction.

- Reversal: These attributes refer to a high degree of achievement resulting in dissatisfaction and to the fact that not all customers are alike.

The following figure shows the dimensions of Kano Model.

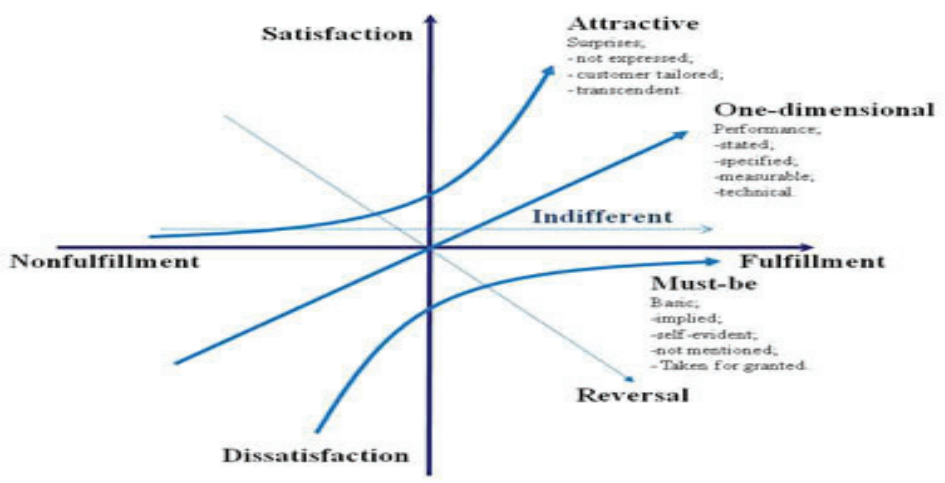

Figure 1: The Kano Model

Source: Matzler and Hinterhuber (1998).

Functional and dysfunctional questions are prepared to identify the preference category of the customer. For example:

Functional question: What will be your feeling if your bike/scooter brand has bike wash service?

1. I like it 
2. I expect it

3. I am neutral

4. I can tolerate

5. I dislike it

Dysfunctional question: What will be your feeling if your bike/scooter brand does not have bike wash service?

1. I like it

2. I expect it

3. I am neutral

4. I can tolerate

5. I dislike it

Cross tab has been used to get the preference category as shown in the following table.

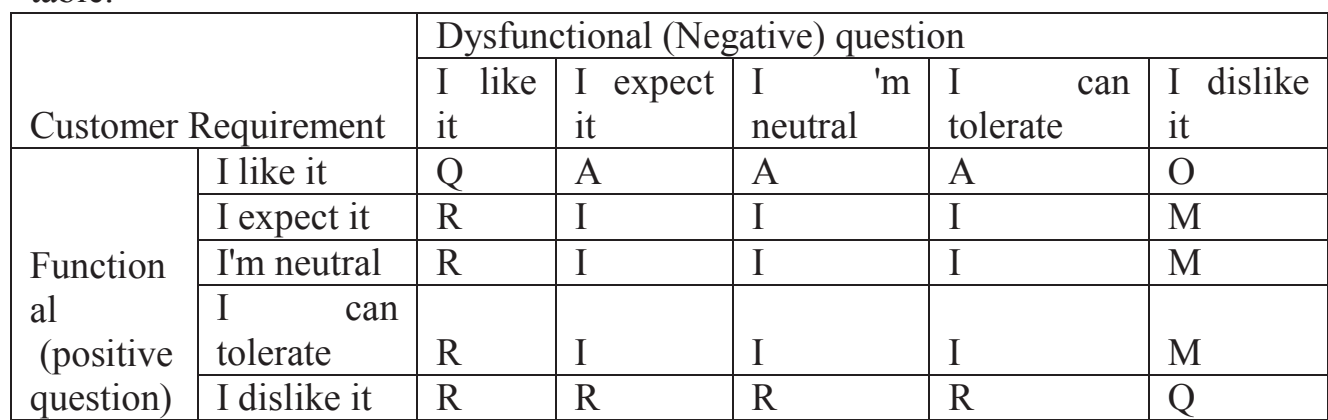

Where customer requirement is:

M -Must-Be, O - One-Dimensional, A- Attractive, R - Reverse, Q -Questionable, I - Indifferent

\section{Customer Satisfaction coefficient}

Customer Satisfaction (CS) coefficient states whether satisfaction can be increased by meeting a product or service requirement, or whether fulfilling this product requirement merely prevents the customer from being dissatisfied. The Customer Satisfaction coefficient is the indicative of how strongly a product or service feature may influence satisfaction or, in case of non-fulfilment, customer dissatisfaction. The positive CS coefficient ranges from 0 to 1 ; the closer the value to 1 , the higher the influence in customer satisfaction. A positive coefficient which 
approaches 0 signifies that there is very little influence. The negative CS coefficient ranges from 0 to -1 . If it approaches to -1 , the influence on customer dissatisfaction is especially strong if the analyzed product or service feature is not fulfilled. A value of 0 signifies that this feature does not cause dissatisfaction if it is not met.

\section{Extent of Satisfaction:}

Satisfaction dimension $=(A+O) /(A+O+M+I)$

\section{Extent of Dissatisfaction:}

Dissatisfaction Dimension $=(0+M) /[(A+O+M+I) *(-1)]$

Where: $\mathrm{M}=$ Must-Be quality, $\mathrm{O}=$ One-Dimensional quality, $\mathrm{A}=$ Attractive quality $\mathrm{I}=$ Indifferent quality

\subsection{The Conceptual Framework}

From the various literature reviews the following model is proposed as conceptual framework.

Here, the identified after sales services from 9 different brands are categorized as major after sales services and the behaviour aspects of services are categorized as supporting after sales services. Since these major and supporting after sales services make an impact on customer satisfaction, they are grouped as independent variables. The demographic variables are the moderating variables and customer satisfaction is treated as dependent variable.

A small structured interview was conducted with the Service Manager or Service In-charge to find out the list of after sales service that the brand is currently offering via service centres. Primary data is collected with the help of structured questionnaire especially designed for this research. The collected data is verified by checking its reliability and validity by using SPSS software. Small portion of KANO model is used to categorize the after sales service in terms of attractive service, must be and one dimension. Secondary data and information is gathered via different internationally credited journals, articles and newsletters. 
Independent Variables:

Major After sales Service

- Repair and Maintenance

- Spare Parts Supply

- Warranty

- Inspection

- Bike wash

- Customer Care

- Service Camp

- Driving Orientation

- Mobile Van (office hour and $24 \mathrm{hrs}$ )

Supporting After-Sales

Service

- Behavior of Technicians

- Cleanliness and comfort of reception or waiting area

- Competency of Technicians

- Overall time taken for one servicing

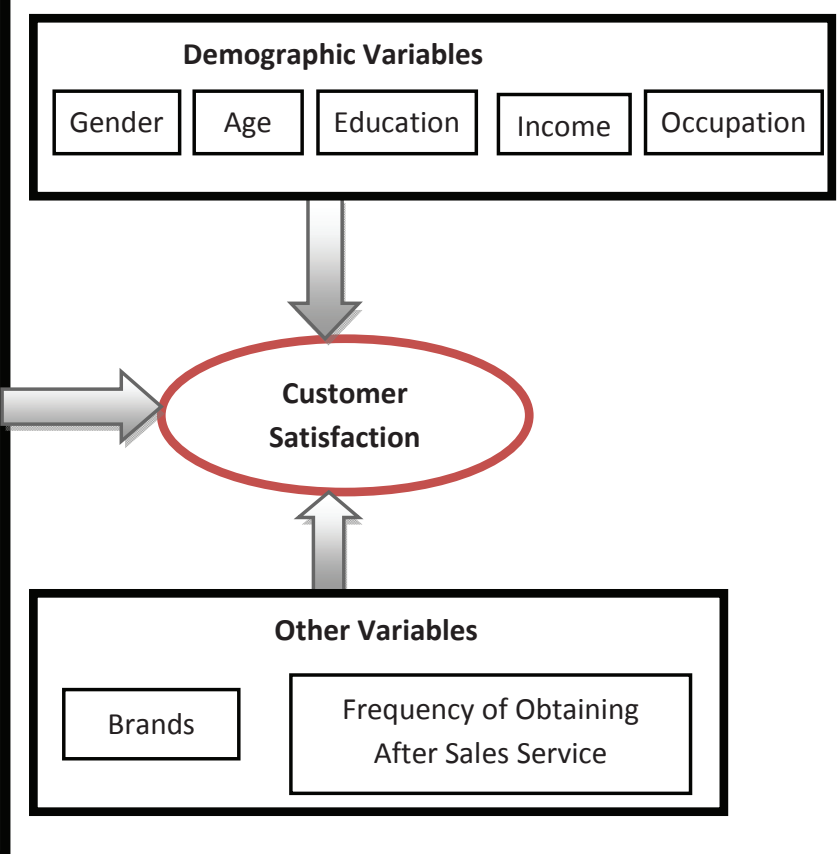

Figure 2: The Conceptual Framework

Non-Probability sampling is used due to unavailability of sample frame. Hence, quota and convenience sampling are used as a sampling technique where quota is defined in terms of current brands of scooter and bikes available in Kathmandu Valley. Currently, there are nine brands capturing market shares for two wheelers: Hero, Honda, Bajaj, Royal Enfield, Mahindra, Yamaha, Suzuki, TVS and VR. Out of nine brands three brands are grouped into other category. (Others= Suzuki, TVS and VR). Hence, for the research, there are 7 categories of brands including others. Thus, the sample size is 280 i.e. 40 from each brands. Personal interviews are conducted with some of the customers and five service providers of various brands.

For this study, quantitative data is collected through survey and data are analyzed through MS Excel and SPSS 17.0 software. For analyzing the data, tools like mean analysis, frequency analysis, correlation, Independent Sample T-Test, F-Test, oneway ANOVA are used on the collected data. Small portions of Kano model are used for data analysis. Qualitative data is collected from the interview and presented in the report. 


\section{Result and Discussion}

\section{1 Data Analysis}

The research comprised of two third male respondents and about one third female respondent. It is found that satisfaction level differs as per gender which is significant at 0.02. Likewise, around one fifth of the respondent fall under the age group (18 to 30), a little more than two fifth of the respondent fall under the age group (30 to 40) and exactly two fifth of the respondent represent the age group 40 and above. It is found that age has no relationship with satisfaction level.

Approximately $20 \%$ had completed plus 2 , around $44 \%$ had completed bachelors and around $36 \%$ had completed masters and above degree. It is found that satisfaction level differs as per education level which is significant at 0.019.

Similarly, the income level of around $29 \%$ respondents is up to Rs. 15000 , approx. $23 \%$ said that their income level fell under Rs (15000-30000); approx. 29\% said that their income level was in between Rs. 30000-45000 and around 19\% respondents said that they earned Rs 45000 and more than that. It is found that satisfaction level differs as per income level which is significant at 0.003.Moreover, around one sixth of the respondents is holding government job, a little more than two sixth of the respondents are engaged in private jobs, a little less than a quarter respondent are the self employed, and around a quarter respondents are students. It is found that there is no relationship between occupation and customer satisfaction.

Around $18 \%$ respondents obtain after sales service up to 3 times, approx. $29 \%$ obtain after sales service 4 to 6 times, a little more than one-sixth of the respondents obtain after sales service 7 to 9 times and a little more than two- sixth of the respondents obtain after sales service for 10 and more times. It is found that satisfaction level differs as per the number of times customers have obtained the after sales service.

The research found out that satisfaction level depends on brands of bike and scooter which was significant at 0.00. On the basis of mean score Royal Enfield with a mean score of 4.2 has the highest level of satisfied customers, and then comes Hero (4.08), and Mahindra (3.85). In the fourth position, we have Bajaj (3.65), Yamaha (3.6), Others (3.58) and Honda (3.35) respectively.

Further, it was found that most of the customers were using repair and maintenance, bike wash, inspection, spare parts and customer care mostly. The research also found that the average ranking for all the statements of repair and maintenance (solution, time, price and overall), spare part supply (access, on time supply, price and overall), warranty (clarity, length, implementation and overall), 
customer care (reminder, feedback call, accuracy and overall), service camp (information, frequency, promotion offers and overall), mobile van (time, price, solution, service hrs and overall), driving orientation (clear cut instructions, duration and overall) and behaviour of technicians (listen, respond, interest, politeness and overall dealing) is more than 3 which means almost all respondents are satisfied with services they are getting under these service headings.

Similarly, the average ranking for inspection, bike wash, cleanliness and comfort of reception area, knowledge of technicians and overall time taken for one servicing is more than 3 which means almost all customers are satisfied with these services.

In addition to this, approx. 93\% respondents said that there was effect of after sales service on their expected level of satisfaction and remaining denied. Trust, reliability and free servicing were the major reasons for going to service centres provided by the brand itself. Only, one fifth of the respondents had complained out the after sales service. Approx. 93\% said that they will revisit their service centres again. Four fifth of the respondents said that they would recommend the brand to their friends and relatives. $76 \%$ said that they would repurchase the same brand on the basis of after sales service.

Result of correlation analysis of after sales service attributes with customer satisfaction is presented in the following table for hypothesis testing.

Table 1: Result of Correlation Analysis of After Sales Service Attributes with Customer Satisfaction

\begin{tabular}{|l|l|l|}
\hline After Sales Service Attributes & Correlation Coefficient & P-value \\
\hline Major & & \\
\hline Repair and Maintenance & 0.535 & 0.000 \\
\hline Spare Parts Supply & 0.364 & 0.000 \\
\hline Warranty & 0.588 & 0.000 \\
\hline Bike Wash & 0.496 & 0.000 \\
\hline Inspection & 0.597 & 0.000 \\
\hline Customer Care & 0.348 & 0.000 \\
\hline Service Camp & 0.364 & 0.000 \\
\hline Driving Orientation & 0.407 & 0.000 \\
\hline Mobile Van & 0.266 & 0.000 \\
\hline Supporting & & \\
\hline Behaviour of Technicians & 0.655 & 0.000 \\
\hline Competency of Technicians & 0.651 & 0.000 \\
\hline Cleanliness and comfort of waiting area & 0.426 & 0.000 \\
\hline Overall Time Taken for One Servicing & 0.547 & 0.000 \\
\hline
\end{tabular}

Table 1 indicates that repair and maintenance has the correlation coefficient greater than zero. This indicates that there is positive correlation between repair and 
maintenance and customer satisfaction (0.535). Since correlation is slightly greater than 0.5 we consider that there is somewhat a strong relationship between satisfaction from repair and maintenance and customer satisfaction. Moreover, pvalue $(0.000)<\alpha(0.05)$, hence, we reject null hypothesis. Thus, there is a significant relationship between repair \& maintenance and customer satisfaction.

Likewise, spare parts have the correlation coefficient greater than zero which indicates the positive correlation between spare parts and customer satisfaction $(0.335)$. Although there is positive correlation, there is weak relationship between satisfaction from spare parts and customer satisfaction as the correlation coefficient is less than 0.5. Moreover, p-value $(0.000)<\alpha(0.05)$, hence, we reject null hypothesis. Thus, there is a significant relationship between spare parts and customer satisfaction.

Similarly, warranty has the correlation coefficient greater than zero which indicates the positive correlation between warranty and customer satisfaction (0.588). Since correlation is greater than 0.5 we consider that there is a strong relationship between satisfaction from warranty service and customer satisfaction. Moreover, $\mathrm{p}$ value $(0.000)<\alpha(0.05)$, hence, we reject null hypothesis. Thus, there is a significant relationship between warranty and customer satisfaction.

Customer care has the correlation coefficient greater than zero which depicts the positive correlation between customer care and customer satisfaction (0.348). Although there is positive correlation, there is weak relationship between satisfaction from customer care and customer satisfaction as the correlation coefficient is less than 0.5. Moreover, p-value $(0.000)<\alpha(0.05)$, hence, we reject null hypothesis. Thus, there is a significant relationship between customer care and customer satisfaction.

Service camp has the correlation coefficient greater than zero which depicts the positive correlation between service camp and customer satisfaction (0.364). However, there is weak relationship between satisfaction from service camp and customer satisfaction as the correlation coefficient is less than 0.5 . Moreover, $p$ value $(0.000)<\alpha(0.05)$, hence, we reject null hypothesis. Thus, there is a significant relationship between service camp and customer satisfaction.

Mobile van service has the correlation coefficient greater than zero which depicts the positive correlation between mobile van service and customer satisfaction (0.266). However, there is weak relationship between satisfaction from mobile van service and customer satisfaction as the correlation coefficient is less than 0.5 . Moreover, p-value $(0.000)<\alpha(0.05)$, hence, we reject null hypothesis. Thus, there is a significant relationship between mobile van service and customer satisfaction. 
Driving orientation service has the correlation coefficient greater than zero which depicts the positive correlation between driving orientation and customer satisfaction (0.407). However, there is weak relationship between satisfaction from driving orientation and customer satisfaction as the correlation coefficient is less than 0.5 . Moreover, $p$-value $(0.000)<\alpha(0.05)$, hence, we reject null hypothesis. Thus, there is a significant relationship between driving orientation and customer satisfaction.

In terms of supporting services, the above table indicates that behaviour of technicians have the correlation coefficient greater than zero which depicts the positive correlation between behaviour of technicians and customer satisfaction (0.655). Since correlation is greater than 0.5 we consider that there is a strong relationship between satisfaction from behaviour of technicians and customer satisfaction.Moreover, p-value $(0.000)<\alpha(0.05)$, hence, we reject null hypothesis. Thus, there is a significant relationship between behaviour of technicians and customer satisfaction.

Problem identification during the inspection has the correlation coefficient greater than zero which depicts the positive correlation between inspection and customer satisfaction (0.597). Since correlation is greater than 0.5 we consider there is a strong relationship between satisfaction from inspection and customer satisfaction.Moreover, $\mathrm{p}$-value $(0.000)<\alpha(0.05)$, hence, we reject null hypothesis. Thus, there is a significant relationship between inspection and customer satisfaction.

Cleanliness of bike or scooter has the correlation coefficient greater than zero which depicts the positive correlation between bike wash and customer satisfaction (0.496). However, there is weak relationship between satisfaction from bike wash and customer satisfaction as the correlation coefficient is less than 0.5. Moreover, p-value $(0.000)<\alpha(0.05)$, hence, we reject null hypothesis. Thus, there is a significant relationship between bike wash and customer satisfaction.

Cleanliness and comfort of reception or waiting area has the correlation coefficient greater than zero which depicts the positive correlation between cleanliness and comfort of reception or waiting area and customer satisfaction (0.426). However, there is weak relationship between satisfaction from mobile van service and customer satisfaction as the correlation coefficient is less than 0.5 . Moreover, $\mathrm{p}$ value $(0.000)<\alpha(0.05)$, hence, we reject null hypothesis. Thus, there is a significant relationship between cleanliness and comfort of reception or waiting area and customer satisfaction. Competency of technicians has the correlation coefficient greater than zero which depicts the positive correlation between competency of technician and customer satisfaction (0.51). Since correlation is 
greater than 0.5 we consider there is a strong relationship between satisfaction from competency of technicians and customer satisfaction. Moreover, p-value $(0.000)<$ $\alpha(0.05)$, hence, we reject null hypothesis. Thus, there is a significant relationship between Competency of technicians and customer satisfaction.

Overall time taken for one servicing has the correlation coefficient greater than zero which depicts the positive correlation between overall time taken for one servicing and customer satisfaction (0.547). Since correlation is greater than 0.5 we consider there is a strong relationship between satisfactions from overall time taken for one servicing and customer satisfaction. Moreover, p-value $(0.000)<\alpha(0.05)$, hence, we reject null hypothesis. Thus, there is a significant relationship between overall time taken for one servicing and customer satisfaction.

Overall, $63 \%$ customers were satisfied with the after sales service and $10 \%$ were very satisfied with the after sales service. Apart from that it was found that 206 customers said that they will recommend as well as repurchase the same brand. Moreover, it was found that there was positive relationship between customer satisfaction and loyalty.

\section{Implication of Kano Model Analysis}

The following table 2 depicts customer response in terms of must-be quality (M), one-dimensional quality $(\mathrm{O})$, attractive quality $(\mathrm{A})$, reverse quality (R), questionable (Q) and indifferent quality (I).

Table 2: Customer Requirement Analysis as per Kano Model

\begin{tabular}{|l|l|l|l|l|l|l|l|l|}
\hline \multirow{2}{*}{ After sales service } & \multicolumn{6}{|c|}{ Customer requirement and frequency } \\
\cline { 2 - 9 } & A & O & M & I & R & Q & Total \\
\hline 1 & Repair and maintenance & 16 & $\mathbf{1 7 5}$ & 89 & 0 & 0 & 0 & 280 \\
\hline 2 & Spare part supply & 32 & 68 & $\mathbf{1 7 2}$ & 8 & 0 & 0 & 280 \\
\hline 3 & Customer care & 22 & $\mathbf{1 4 9}$ & 101 & 8 & 0 & 0 & 280 \\
\hline 4 & Bike wash & 54 & 58 & $\mathbf{1 1 9}$ & 49 & 0 & 0 & 280 \\
\hline 5 & Inspection & 32 & $\mathbf{1 3 9}$ & 87 & 22 & 0 & 0 & 280 \\
\hline 6 & Warranty & 14 & 38 & $\mathbf{2 0 4}$ & 24 & 0 & 0 & 280 \\
\hline 7 & Driving orientation & $\mathbf{1 1 8}$ & 39 & 17 & 106 & 0 & 0 & 280 \\
\hline 8 & Mobile van (office hours) & 43 & $\mathbf{1 0 4}$ & 97 & 36 & 0 & 0 & 280 \\
\hline 9 & Service camps & 41 & 51 & $\mathbf{1 2 2}$ & 66 & 0 & 0 & 280 \\
\hline 10 & 24 hours mobile van & $\mathbf{1 1 8}$ & 16 & 30 & 116 & 0 & 0 & 280 \\
\hline
\end{tabular}

From the survey of functional and dysfunctional question which was collected from 280 respondents, it was found that customers believed that Spare part supply, Warranty, Bike wash and Service camp are the must be requirement. Must be requirement includes all those service or features which customer expect from the service provider. Once you involve in the purchase agreement with the seller, you 
expect some of the services to be present. Hence, these are the inherent services that you expect from your service provider. Must-be requirements are also called Threshold Attribute.

Likewise, Repair and Maintenance, Customer Care, Inspection and Mobile Van (office hours) are regarded as one-dimensional services. One-Dimensional Attribute includes all those service or features which customer demands or verbalizes and fulfilment of these features will leads to customer satisfaction. OneDimensional attributes are also called Performance attributes. Customers always want these performance attribute to serve them. More of it or betterment of it will improve customer satisfaction. The price for which customer is willing to pay for a product is closely tied to performance attribute.

And, as per the customer, Driving Orientation and 24 hours Mobile Van service are Attractive services. Attractive Attributes are those attributes of features which customers were not expecting, but received as bonus. Attractive attributes are also called excitement attributes which are unspoken and unexpected by customers but presence of these features can result into high levels of customer satisfaction, however their absence does not lead to dissatisfaction. By providing attractive attributes, company can gain competitive advantage as well.

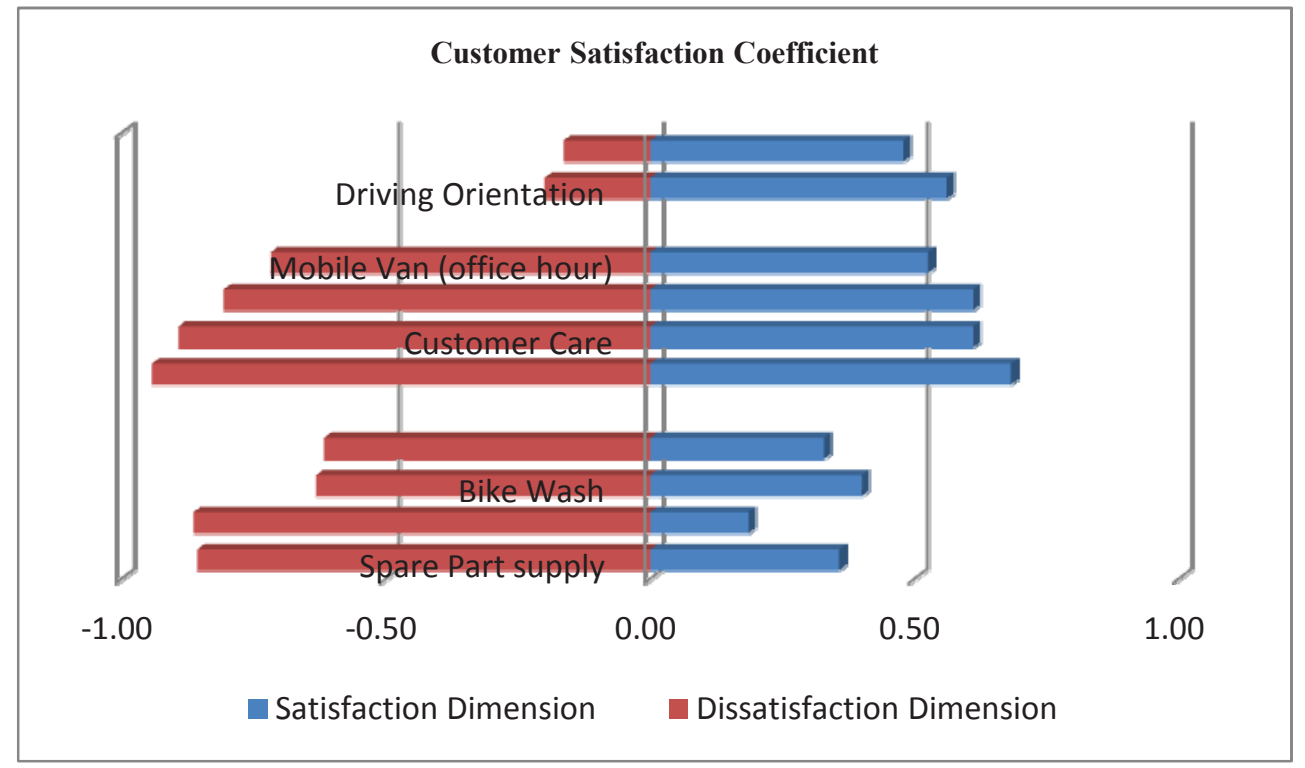

Figure 3: Customer Satisfaction Coefficients

Figure 3 shows CS coefficient indicating extent of satisfaction and extent of dissatisfaction. In case of Must-be attribute, all the service variables -spare parts, 
warranty, bike wash and service camp- have satisfaction dimension less than 0.5 and dissatisfaction dimension more than -0.5 . This indicates that if these service variables or features are fulfilled then they would not add more value to satisfaction level; however, if these services are not fulfilled or delivered properly then it will lead to high customer dissatisfaction. Hence, these must be attributes need to be fulfilled by the players of two wheelers in Kathmandu Valley.

Likewise, in case of One-Dimensional attribute, all the service variables or features like repair and maintenance, customer care, inspection and mobile van (office hours) have satisfaction dimension more than 0.5 and dissatisfaction dimension more than -0.5 . This indicates that if these service variables are fulfilled then they will have positive impact on customer satisfaction; however, if they are not fulfilled then they can be the reason for customer dissatisfaction. Since, one dimensional attributes are demanded by the customers, proper fulfilment enhances satisfaction; and failure to incorporate these services leads to extreme dissatisfaction.

Similarly, in case of Attractive attribute, service variables like driving orientation and 24 hrs mobile van have satisfaction dimension almost or more than 0.5 and dissatisfaction dimension less than -0.5 or almost close to 0 . This indicates that fulfilment of these attractive attributes increases customer satisfaction, or to some extent, they will delight the customers but even in case of non fulfilment they will not make customers dissatisfied.

From the observation and interview with some of the customers and service provider, it is found that some of the customers are totally satisfied with the after sales service, however, most of the customers are unaware about all the after sales service that their current brand is offering. They are also dissatisfied with the unmaintained standards of after sales service. Service Providers said that customers themselves do not show much interest to know about the after sales services and do not come for servicing even when they are informed via newspapers. They agreed that they did not have same service standard throughout the valley but they were trying to maintain it. Apart from that, they believed that despite the fact that only satisfied customers would be loyal customers and would help business to grow, they were not able to have 100 percent satisfied customers. Moreover, they shared that service had always been a scapegoat so whenever sales decreased management started raising question on service. They agreed that customer satisfaction could only be obtained with the help of effective after sales service.

\section{Concluding Remarks}

The main purpose of this study is to examine the relationship between identified after sale services and customer satisfaction in the two wheeler industry. It is 
concluded that the behaviour of technicians has the strongest positive relationship with customer satisfaction. The second determinant for customer satisfaction in two wheeler business is competency of technicians. In case of supporting after sales service, overall time taken for one servicing has strong and positive relationship whereas, cleanliness and comfort of reception area have positive but weak relationship as correlation coefficient is less than 0.5. In terms of major after sales service, repair and maintenance, warranty and inspection have strong and positive relationship with customer satisfaction. However, spare parts supply, customer care, service camp, mobile van, driving orientation and bike wash have positive but weak relationship with customer satisfaction.

Surprisingly, the customers' satisfaction of two wheeler business relies mainly onsupporting after sales service rather than major after sales service in Kathmandu Valley. It can be inferred that behaviour attributes plays key role in customer satisfaction.

In nutshell, driving orientation and $24 \mathrm{hrs}$ mobile van services are attractive attributes and can increase customers' satisfaction level if fulfilled but do not lead to extreme dissatisfaction if not provided. Likewise, it is concluded that spare part supply, warranty, bike wash and service camp are must- be attributes which increase customer dissatisfaction if not fulfilled but fulfilment of these attributes does not contribute much in customer satisfaction. Similarly, it was found that repair and maintenance, customer care, inspection and mobile van are one dimensional attribute and if fulfilled they will increase customer satisfaction.

Mustofa and Abebe (2012) found thatdriving orientation doesn't contribute to customer satisfaction in Ethopia, however, this research depicts driving orientation as attractive attribute that can make customer delight. This implies that customer satisfaction varies with place and brand.

It is found that Royal Enfield has the highest number of satisfied customers in comparison with its counterparts. More than half of the customers are satisfied with current after sales services provided by their respective brands. It is concluded that service providers believes that after sales service can increase customer satisfaction and ultimately make customers loyal.

The interview and observation raises questions regarding some issues. For instances, in terms of service standard, customers are raising issues like uneven services in various service centres of the same brand. Also some information issues like how after sales service information should be provided to customers i.e. whether customers should ask for the information or service providers themselves should try to provide information regarding after sale service etc. Hence, these can be the subject of further research. 
After this research, two Wheeler brands are strongly recommended to provide technical expertise and customer relations management trainings to technicians. Along with that it is recommended to carry out Kano Model Analysis with some fixed interval of time as all after sales attributes have no equal contribution to overall satisfaction levels. This study is significant to distributors of two wheelers and parent companies as they can formulate after sales service strategies by understanding the present satisfaction level of customers and degree of each after sales service attribute to satisfy the customers.

Budget constraint, response and non response errors and limited study area are some of the limitation of this research. Likewise, detail qualitative approach would have enlightened the research.

\section{REFERENCES}

Berman, B. (2005). How to delight your customer. California Management Review 48 (1), 129-151.

Bloemer, M. M., \& Pauwels, K. H. (1998). Explaining brand loyalty, dealer sales loyalty and dealer after sales loyalty: the influence of satisfaction with the car, satisfaction with the sales service and satisfaction with the after sales service. Journal of consumer satisfaction, dissatisfaction and complaining behaviour $11,78-90$.

Cabuk, Y., Karayilmazlar, S., \& Turedi, H. (2012). A study on evaluation of after sales services in the furniture sector. Bartin Orman Fakulteis 14 (22), 1-11.

Dua, K., \& Dua, S. (2013). A study of customer satisfaction with reference to tata motor passenger vehicles. International Journal of Advanced Research in Management and Social Sciences 2(4), 68-83.

Economic Education. (2012). After Sales Service. Retrieved from http://neweconomicseducation.blogspot.com/2012/02/after-sales-service.html

Fenghua, X., Xiaoye, Z., \& Yuqing, Y. (2013). Analysis of Haier home appliance after -sales service recovery illustrated by the case of Jiaxing. Journal of Applied Science 13(9), 1661-1664.

Gang, L., \& Shuqin, W. (2012). an empirical study of after-sales service relationship in China's auto industry. A paper presented in International Conference on Mechanical Engineering and Material Science (MEMS 2012) held in Shanghai, China; December (28-30)

Giri, Sanjupa (2015). Study of after sales service quality attribute of two wheeler on customer satisfaction in Kathmandu Valley (1-117) 
Hallowell, R. (1996). The relationships of customer satisfaction, customer loyalty, and profitability: an empirical study. International Journal of Service Industry Management 7(4), 27-42.

Hussain, N., Batti, W. A., \& Jilani, A. (2011). An empirical analysis of after sales service and customer satisfaction. Management \& Marketing Challenges for the Knowledge Society 6(4), 561-572.

Ilyas, A., Nasir, H., Malik, M. R., Mirza, U. E., Munir S., \& Sajid, A. (2013). Assessing the service quality of bank using SERVQUAL model. Interdisciplinary Journal of Contemporary Research in Business 4(11), 390400.

Katarne, R., \& Sharma, S. (2010). Measurement of service quality of an automobile service centre. A paper presented in International Conference on Industrial Engineering and Operations Management held in Dhaka, Bangladesh; January $(9-10)$.

Ladokun, I. O., Adeyemo, S. A., \& Ogunleye, P. O. (2013). Impact of after -sales service on consumer satisfaction and retention: a study of LG electronics in Ibadan, Nigeria. Journal of Business and Management 11 (4), 54-58.

Lucero, L. C., Legorreta, S. L., \& Cervantes, T. G. (2007). Factors that influence the brand loyalty and dealer loyalty of the automotive industry: The case of Mexican consumers in the central region of Mexico. Latin American Advances in Consumer Research 2, 233-237.

Maghsoudlou, Z., Mehrani, H., \& Azma, F. (2014). The role of after-sales service in customer satisfaction: case study (Samsung house appliances). International Research Journal of Management Sciences 2(6), 175-179.

Matzler, K., \& Hinterhuber, H. H. (1998). How to make product development projects more successful by integrating Kano's model of customer satisfaction into quality function deployment. Technovation, 18(1), 25-38.

Mishra, A. K. (2014). A study on relation between effective after sales service and customer overall satisfaction at TATA motor's with special reference to Ramgarhia automobiles Ramgarh Cantt, Jharkhand. International Journal of Research in Business Management 2(3), 79-88.

Mustofa, K. E., \& Abede, M. K. (2012). Effect of after sale services on customer satisfaction and loyalty in automotive industry of Ethiopia. Advertisement and Marketing. Lambert Academic Publishing, pp.128. 
Saeed, R., Lodhi, R. N., Majid, M. B., Iqbal, R., Mahmood, Z., \& Ahmad, M. (2013). Impact of 'after sales service' on 'consumer buying behaviour' in Sahiwal Pakistan. Management and Administrative Sciences Review 2(5), $555-562$.

Sandhu, M.H., Mahasan, S.S., Rehman, A. U., \& Muzaffar, S. (2013). Service quality dimensions impact on customer satisfaction in telecom sector of Pakistan. Journal of Basic and Applied Scientific Research 3(8), 27-34.

Sauerwein, E., Bailom, F., Matzler, K., \& Hinterhuber, H. H. (1996). The Kano Model: How to delight your customer. A seminar paper presented in International Working Seminar on Production Economics held in Austria, February (19-23), 313 -327.

Shaharudin, M. R., Yusof, K. M., Elias, S. J., \& Mansor, S. W. (2009). Factors affecting customer satisfaction in after-sales service of Malaysian electronic business market. Canadian Social Science, 5(6), 10-18.

Shaikh, F. H. (2012). A critical analysis of consumer buying behaviour of two wheelers (observations pertinent to Ahmednagar city, Maharashtra). Indian Streams Research Journal 2(7), 1-7.

Singh, A., \& Srivatava, M. (2013). Factors affecting customer satisfaction: a study on Maruti Suzuki. International Journal of Advanced Research in Computer Science and Software Engineering 3(5), 865-874.

Srinivasan, K., \& Sharma, R. (2011). A study on customer satisfaction with reference to product characteristics and services of Schwing Stetter India Private Limited.Opinion, 1(1), 58-63.

Tazreen, S. (2012). An empirical study of SERVQUAL as a tool for service quality measurement. Journal of Business and Management 1(5), 9-19.

Yuvaraju, D., \& Rao, S. D. (2014). Customer satisfaction towards Honda two wheelers: A case study in Tirupati. Journal of Business and Management $16(5), 65-74$. 